\title{
Alcohol Use, High Risk Behaviors, and Experiences of Discrimination among Transgender Women in the Dominican Republic
}

Kristine R. Hearld ${ }^{*}$, Adrienne N. Milner ${ }^{2}$, Henna Budhwani ${ }^{1}$, Nicole Abreau ${ }^{3}$, Rosa Mayra Rodriguez-Lauzurique $^{3,4}$, Rebecca Charow ${ }^{4}$, and Robert Paulino-Ramirez ${ }^{3,4}$

1: University of Alabama at Birmingham, 1665 University Boulevard, Birmingham, AL 35294

2: Queen Mary University of London, 58 Turner Street, London E1 2AB

3: Instituto de Medicina Tropical \& Salud Global, Universidad Iberoamericana-UNIBE, Calle Majoma 13, Los Rios, Santo Domingo,

República Dominicana

4: Centro de Orientacion e Investigacion Integral (COIN), Calle Arzobispo Merino, Santo Domingo, República Dominicana

Corresponding: $\quad$ Kristine R. Hearld, Ph.D.

University of Alabama at Birmingham

563 School of Health Profession Building

1705 University Boulevard

Birmingham, AL 35294

Phone: (205) 934-1670

Fax: (205) 975-6608

khearld@uab.edu

Keywords: $\quad$ Transgender; Dominican Republic; Sex Work; Stigma; Alcohol

Journal: $\quad$ Global Public Health (references APA style, 6500 words)

https://www.tandfonline.com/action/authorSubmission?journalCode $=r$ gph20\&page=instructions\#prep 


\section{ABSTRACT}

This study examines associations between alcohol use, high risk sexual behaviors, and experiences of stigma among transgender women across the Dominican Republic. Data from the 2015 Transgender Health Needs Study were analyzed using bivariate analyses $(\mathrm{N}=291)$. High rates of stigma, verbal abuse, alcohol use, and sex work were found. and were associated with each other. Almost 45\% of regular alcohol users are engaging in sex work (43.6\%), compared with $31.1 \%$ of the non-regular alcohol users $(\chi 2=4.82, p<0.05)$. Having sex under the influence of alcohol is statistically associated with high risk behaviors, such as engaging in sex work, sometimes or never using a condom when receiving anal sex, and higher numbers of sexual partners. Furthermore, transgender women who have had sex under the influence of alcohol report statistically significantly higher levels of verbal abuse, discrimination, and levels of perceived transgender stigma. Findings suggest that although anti-discrimination laws exist, policies may not protect transgender women from experiencing stigma and discrimination at work, potentially forcing them to seek alternative careers and engage in behaviors that expose them to greater personal risk and harm. This intersection of factors may indicate a notable public health gap in transgender health in the Dominican Republic. 


\section{INTRODUCTION}

Although studies of transgender individuals increasingly elucidate the experiences and health needs of this population (Budhwani et al., 2017a; Budhwani et al., 2017b), notable scientific and practice gaps persist. In particular, there is insufficient research on transgender individuals in resource-constrained settings (Budhwani, Hearld, Hasbún, et al., 2017; Q. Li, Li, \& Stanton, 2010; Winter et al., 2016), and the limited studies that are available often focus on HIV with less attention given to the high-risk behaviours that contribute to HIV transmission and a host of other diseases (Baral, Poteat, Strömdahl, et al., 2013; Budhwani, Turan, Hasbun, et al., 2017; Winter, Diamond, Green, et al., 2016; Winter, Settle, Reisner, et al., 2016). In countries such as the Dominican Republic where non-traditional gender identities are viewed with contempt, transgender individuals' experiences of stigma and trauma are often exacerbated (Budhwani et al., 2017b; Winter, Diamond, Green, et al., 2016). And these negative experiences may be associated with coping mechanisms such as alcohol use, alcohol abuse, drug use, and high-risk sexual behaviours, particularly in highlyconservative, resource-constrained settings where the transgender population may lack governmental protections (Hasbún, 2012; Reback \& Fletcher, 2014; Sausa, Keatley, \& Operario, 2007; Winter, Diamond, Green, et al., 2016; World Health Organization [WHO], 2014).

According to the World Health Organization (2014), the excessive use of alcohol causes 5.9\% of all deaths worldwide. Alcohol consumption inhibits cognition and judgment, and as such, increases the likelihood of unprotected sex and other sexual risk behaviours (Cooper, 2002; Bryant, Nelson, Braithwaite, \& Roach, 2010; Woolf-King \& Maisto, 2011). Studies exploring the use of alcohol and other drugs among lesbian, gay, bisexual and transgender (LGBT) individuals suggest that substance use and abuse is two to four times higher in sexual and gender minorities than in their heterosexual and cisgender counterparts 
(Leonard et al., 2012; Kelly, Davis, \& Schlesinger, 2015; Smith, Lindsay, \& Rosenthal, 1999). There are a multitude of factors which influence transgender populations’ vulnerability to high-risk behaviors such as excessive alcohol use including stigma, discrimination, and abuse (Baral, Logie, Grosso, Wirtz, \& Beyrer, 2013; Operario \& Nemoto, 2010; Poundstone, Strathdee, \& Celentano, 2004; Sugano, Nemoto, \& Operario, 2006).

Pervasive discrimination and internalized stigma experienced by transgender individuals has been found to impact mental health and contribute to alcohol and other substance abuse as well as depression, anxiety, and suicidal ideation (Clements-Nolle, Marx, Guzman, \& Katz, 2001; Operario \& Nemoto, 2010; Poteat, et al., 2015; Stotzer, 2009; Winter, Diamond, Green, et al., 2016). Scholars have suggested that alcohol consumption may be a coping mechanism for widespread stigma experienced by transgender populations, particularly in resource-constrained settings (Hasbún, 2012; Reback, Rünger, \& Fletcher, 2017; Reback \& Fletcher, 2014)

Also important, when a population is stigmatized with negative views held by large swaths of the general population, this stigma can create barriers to healthcare access, especially mental health care for substance use and abuse (Bulent et al., 2017; Roche \& Keith, 2014). In fact, one third of transgender women in the Dominican Republic believed that it difficult to access health care due to fear of rejection, shame, and embarrassment (Hasbún, 2012); this fear reduces the likelihood that transgender women will seek mental health care to address substance misuse (Hasbún, 2012). Moreover, certain governmental policies allow for the perpetuation of discrimination. In the Dominican Republic, although Article 42, the right to integrity, and Article 39, the right to equality, stipulates that all men and women have the right to live without violence and cannot be discriminated against based on gender and other personal and social conditions, Article 330 of the Criminal Code is often used by police officers to justify harassment, fines, or up to two years of imprisonment when 
transgender and same-sex couples engage in public displays of affection as a violation of decorum and good behaviour in public (Dominican Republic Constitution, 2015).

Furthermore, there are no explicit discrimination protection laws and so, technically it is not illegal to discriminate against transgender persons on account of sexual orientation or gender identity in employment. Thus, transgender women may not be able to find work, and if they do find work which includes interaction with the wider community (e.g. hairdresser, laundry, etc.), customers may not feel comfortable engaging with transgender staff. This necessitates transgender women to seek alternative employment to support themselves and their families. Prior studies (De Graaf, Vanwesenbeeck, Van Zessen, Straver, \& Visser, 1995; Justus, Finn, \& Steinmetz, 2000; Nadal, Davidoff, \& Fujii-Doe, 2014) have shown that a common alternative career for transgender women is sex work, which ultimately makes an already high-risk population even more vulnerable to stigma and abuse, often resulting in their engagement in coping mechanisms and riskier sexual behaviours.

Considering the significant exposure to stigma and abuse that transgender women in resource-constrained settings encounter, the use of alcohol as a coping mechanism in both high-income and low-income nations, and the current stigmatizing policies that exist in the Dominican Republic that allow for employment discrimination, we examined the associations between stigma, abuse, alcohol use, and sex work in a national sample of transgender women in the Dominican Republic. We hypothesized that experiences of stigma and abuse would be associated with alcohol use and that engagement in sex work would also be associated with alcohol use in the Dominican Republic.

\section{METHODS}

Data for this study was from the 2015 Dominican Republic Transgender Health Needs Study (THNS), collected by Centro de Orientación e Investigación Integral (COIN), and funded by 
the National Council for HIV and AIDS (CONAVIHSIDA) representing the Dominican Republic Ministry of Health. The criteria for inclusion were to be a biological male, presenting as and self-identifying with the female gender. Transgender community-based organization leaders from Trans Amigas Siempre Amigas, Coalicion de Mujeres Trans, Trasvesti y Transexuales Trabajadores Sexuales, and Trans Este Podemos Avanzar were engaged in design, validation, and implementation of this questionnaire. Prior to this study, this specific questionnaire was implemented and validated in Central American countries in order to measure the health needs of their transgender populations. This questionnaire was adapted to the linguistic Spanish dialect of the Dominican Republic.

As recommended by the Joint United Nations Programme on HIV/AIDS (UNAIDS), this study leveraged the PLACE method of data collection (Weir et al., 2005). The study employed snowball sampling using peers from the different communities (Rao et al., 2017; Shaghaghi, Bhopal, \& Sheikh, 2011). Data was collected from transgender women in Santo Domingo, La Altagracia, Puerto Plata, Santiago, Dajabón, Independencia, and Barahona. The Ministry of Health’s internal surveillance data on locations where the most-at-risk HIV infections are located informed site selection, and included the United States President's Emergency Plan for AIDS Relief's (PEPFAR) priority provinces. Interviews were conducted in neutral spaces, such as restaurants, parks, etc., which were recommended by the local transgender community and community-based organizations working in study communities.

\section{Ethical Approval}

The National Bioethical Committee, (CONABIOS in Spanish) (\#035-2016), and the Institutional Review Board at Universidad Iberoamericana (\#CEI2016-04), provided exemption from ethical approval. Informed consent was collected verbally, as well designed and implemented verbal consent in participatory action research can lead to increased 
voluntary participation and thorough study comprehension when working with low literacy populations (Krogstad et al., 2010; Marshall, 2007; Tekola et al., 2009; Onvomaha Tindana, Kass, \& Akwenogo, 2006). Verbal consent was witnessed by a senior investigator and the process involved three steps: 1) provision of a thorough verbal description about the participant's rights and the study purpose in simple language, 2) an explanation of topics covered, and 3) request of verbal consent that she is participating freely, without coercion. The University of Alabama at Birmingham’s Institutional Review Board provided ethical approval for secondary data analysis (\#N150803004).

\section{Survey Measures}

Three categories of variables were measured: demographics, high-risk behaviors, and experiences with stigma, discrimination, and abuse. Demographic variables included age, education, income in Pesos, employment status, and relationship status. Age was measured as a continuous variable. Education was measured in three categories: secondary education or less, secondary completed, and higher than secondary education. Monthly income was measured with a dichotomous variable indicting whether the participant had very low monthly income or not. Respondents reporting earning 5,000 or less Pesos were coded as having low monthly income (1). Respondents reporting earning more than 5,000 Pesos were coded as not having low monthly income (0). Finally, respondents reporting being employed were coded as 1 for employment and unemployed transgender women were coded as 0 . We assessed relationship status with a categorical variable consisting of married or living together, in a relationship but not living together, polyamorous, and no current partner.

High-risk behaviors were assessed by engagement in sex work, if the respondent has not had an HIV test in the last 12 months, non-consistent use of condoms when receiving anal sex in the past 30 days, the number of sexual partners in the last 6 months, and alcohol use. 
We assessed engagement in sex work through two questions. The first question asked the participant what work they do, and sex work was a response option. The second question asked “Apart from your work, what other manners do you have to supplement your income (aka other sources of income)?” For this question, sexual client was a response option. Respondents that responded that they were involved in sex work as the primary or an additional income source were coded as 1 for sex work involvement. Respondents that did not respond that they were involved in sex work as an income source were coded as 0 . HIV testing history was assessed by asking respondents if they had received an HIV test in the past 12 months ( $1=$ no HIV test in past 12 months, $0=$ HIV test in past 12 months). Study participants were asked about condom use during anal sex when being penetrated. Respondents that reported using a condom sometimes or never were coded as 1 to each question, and respondents that reported always using a condom were coded as 0 . Number of sexual partners in the last 6 months was assessed with a continuous variable. Alcohol use was measured with two dichotomous variables: regular alcohol use and alcohol use during sexual activity. For regular alcohol use, we used the question: "Please indicate in what frequency you used alcohol in the past 12 months. (a) daily; (b) one time a week; (c) multiple times a month; (c) multiple times during the past 6 months; and (d) I do not use alcohol.” Respondents that reported "daily” or "one time a week" were coded as a regular alcohol user (1). Likewise, respondents that reported using alcohol less than one time a week were coded as not a regular alcohol user (0). Alcohol use during sexual activity was assessed using the following question: "In the past 30 days, have you had oral, anal, or vaginal sex under the influence of some of the following drugs? Alcohol?” Respondents that reported yes were coded as having had sex under the influence of alcohol (1) and respondents that reported no were coded as not having had sex under the influence of alcohol (0). 
Stigma and abuse were assessed by perceived transgender stigma experienced, recent experiences of verbal and physical abuse, and recent experiences with employment difficulties. Stigma was measured on a 0-9 scale (Cronbach's $\alpha=.827$ ) and measured how many times in the past 3 months the respondent had experienced the following events specifically due to the fact that [she] is a trans person': 1) arguments between her parents, 2) problems with her brothers or sisters, 3) arguments between her and her parents, 4) arguments with other family members, 5) problems with her professors or bosses, 6) problems with classmates or coworkers, 7) arguments or disagreements with close friends, 8) lost close friendships, 9) problems with the police or other authorities. Family Health International (FHI) originally employed this stigma scale during their 2012 National Surveillance Study conducted in the Dominican Republic. These measures were originally developed for use with men who have sex with men (MSM, which was the broad category within which transgender women were classified previously), and were therefore adjusted during the pilot testing phase of this study for acceptability amongst transgender populations. Respondents were asked if they had experienced verbal insults or physical abuse in the last 3 months. Finally, respondents were asked if they had been denied a job or fired form one in the last 3 months.

\section{Statistical Analyses}

We performed descriptive analyses for demographics, high risk behaviors, and stigma and discrimination variables in order to examine frequencies and proportions and means and standard deviations. Bivariate analysis (t-tests and chi-square tests) examined differences between routine alcohol users and abstainers and between alcohol users during sexual activity and abstainers (n=291). All analyses were conducted using Stata 15. 


\section{RESULTS}

\section{Descriptive Statistics}

Table 1 presents univariate results. About half of the respondents reported drinking alcohol once a week or more (48.1\%), and half of respondents (49.5\%) had sex under the influence of alcohol in the last 30 days. Average age of our sample was 26 years, ranging from 18 to 68 years. Almost $45 \%$ of respondents reported a monthly income of 5,000 Pesos or less (44.8\%), and $11.7 \%$ were unemployed. Approximately $37 \%$ of the sample has engaged in sex work (37.1\%) and almost 20 percent of the sample has not had a HIV test in the last 12 months (19.2\%). On average, respondents had 10.3 sexual partners in the past 6 months. Around 14\% of the sample did not consistently use a condom when receiving anal sex in the past 30 days (13.8\%). The majority of this national sample did not have a current partner (67.3\%) and 21.7\% considered themselves to be polyamorous. Eight out of ten respondents had been denied a job or fired from one in the last three months (80.3\%) and half of the sample had experienced verbal insults in the last 3 months (47.9\%). About $14 \%$ of the sample had experienced physical abuse in the last 3 months.

[Table 1 about here]

Bivariate associations are found on Table 2. Over $43 \%$ of respondents who are regular alcohol drinkers answered that they engage in sex work (43.5\%), compared to $31.1 \%$ of the TGW who are not regular alcohol drinkers $(\chi 2=4.82, \mathrm{p}<0.05)$. Likewise, approximately $50 \%$ of respondents who have had sex under the influence of alcohol in the last 30 days are engaged in sex work (49.3\%), compared to $25.1 \%$ of respondents who did not have sex under the influence of alcohol in the last 30 days and are engaged in sex work $(\chi 2=18.16, p<0.001)$. Approximately 5\% of respondents who are regular alcohol drinkers had not received an HIV 
test in the last 12 months (5.1\%), compared to $11.5 \%$ of respondents who are not regular alcohol drinkers $(\chi 2=3.82, \mathrm{p}=0.05)$. Likewise, $2.9 \%$ of respondents had sex under the influence of alcohol in the last 30 days and had not received an HIV test in the last 12 months, compared to $13.6 \%$ of the respondents who did not have sex under the influence of alcohol in the last 30 days and have had not received an HIV test in the last 12 months $(\chi 2=3.82, \mathrm{p}=0.001)$

Approximately $18 \%$ of respondents who had sex under the influence of alcohol in the last 30 days reported sometimes or never using a condom when receiving anal sex in the past 30 days (17.8\%). This is compared to $7.7 \%$ of the respondents who did not have sex under the influence of alcohol in the last 30 days $(\chi 2=4.04, p<0.05)$. On average, respondents who had sex under the influence of alcohol in the last 30 days had 13.8 sexual partners in the last six months, compared to the average of 6.8 sexual partners for the respondents who did not have sex under the influence of alcohol in the last 30 days $(\mathrm{t}=2.32, \mathrm{p}<0.05)$.

Experienced stigma or abuse are associated with having had sex under the influence of alcohol in the last 30 days. Approximately 58\% of respondents who had sex under the influence of alcohol in the last 30 days reported experiencing verbal insults in the last 3 months (57.6\%), compared to $38.4 \%$ of the respondents who did not have sex under the influence of alcohol in the last 30 days $(\chi 2=10.80, p<0.001)$. Likewise, $19.6 \%$ of respondents who had sex under the influence of alcohol in the last 30 days reported experiencing physical abuse in the last 3 months, compared to $8.8 \%$ of respondents who did not have sex under the influence of alcohol in the last 30 days $(\chi 2=6.88, \mathrm{p}<0.01)$. Thirty percent of respondents who had sex under the influence of alcohol in the last 30 days reported being denied a job or fired from one in the last 3 months (29.4\%), compared to $10.2 \%$ who did not have sex under the influence of alcohol in the last 30 days $(\chi 2=16.86, \mathrm{p}<0.001)$. Finally, on average respondents who have had sex under the influence of alcohol in the last 30 days report higher levels of 
stigma ( $M=4.03)$, compared with respondents who did not have sex under the influence of alcohol in the last 30 days $(\mathrm{M}=3.11 ; \mathrm{t}=-2.70, \mathrm{p}<0.01)$.

\section{DISCUSSION}

Considering findings from prior literature, we hypothesized and found for support for associations between 1) stigma and abuse, and 2)alcohol use and sex work in this national sample of transgender women residing in the Dominican Republic. Sex workers, respondents who engaged in high-risk sexual behaviors, those who used condoms less frequently, and respondents reporting higher numbers of sexual partners were all more likely to consume alcohol regularlyStatistically significant relationships were found between having experienced stigma, verbal abuse, physical abuse, sex work, lack of condom use, and having been denied a job or having been terminated from a job and use of alcohol during sex. Alcohol use was highly correlated with most of our variables of interest, including HIV testing. Regular alcohol drinkers and those who had sex under influence of alcohol were more likely to have taken an HIV test in the past six months. This unanticipated finding is of particular interest, because it potentially highlights the expression of individual self-efficacy through the application of knowledge -- in that respondents who engaged in these high-risk behaviors understood their elevated risk for contracting HIV, and therefore, opted to take HIV tests. The finding that alcohol use was associated with multiple high-risk behaviors is particularly alarming considering routine alcohol use can lead to addiction and a known coping mechanism for trauma, which is often experienced by transgender women globally.

Our results provide additional support for the growing body of literature which notes that transgender women, particularly transgender women in resource-constrained settings, experience stigma, discrimination, and abuse, and ongoing exposure to this triad is interconnected with substance use. Extending this further, we assess that this alcohol 
consumption that is related to brutal life experiences, may facilitate high-risk sexual behaviors putting transgender women at greater risk for contracting HIV and sexually transmitted infections. This all beg the question, where should public health interventionists intervene? Government policy should protect citizens from stigma and discrimination, but in the case policy does so insufficiently, what is of greatest priority - reduction in alcohol use or reduction in high-risk sexual behaviors?

\section{Limitations}

First, bias is to be expected in self-reported survey data, especially when the topic is perceived to be controversial (sex work, alcohol use, stigma) or study population is stigmatized (transgender women). Second, some of the measures lacked specificity, reducing extensibility of our findings. For instance, although the survey assessed alcohol use while engaging in sex, it did not specifically ask is the alcohol consumed was to facilitate the behavior or if the alcohol made the respondent more willing to engage in high-risk behaviors. Furthermore, although data was collected on frequency of alcohol use, the amount and type of alcohol consumed was not included in the survey. Third, the survey doesn't parse sex work by partner type (e.g. coercive, regular, or client) which has been particularly informative in prior studies out of the Latin American and Caribbean region. Fourth, although the sample is national, because snowball sampling was used, findings may not be fully generalizable. Finally, causality cannot be inferred from cross-sectional data; therefore we are unable to assess the order of stigma or abuse exposure, alcohol use, engagement in high-risk sexual behaviors, and sex work.

\section{Conclusion}

Significant knowledge gaps persist related to research with transgender populations in resource-constrained settings, particularly in the Spanish-speaking Caribbean. Although 
cross-sectional data cannot offer causal inferences, the associations between stigma and abuse, alcohol use, and sex work in the transgender women from our national sample is concerning, considering alcohol use is a well-documented associate of engagement in HIV high-risk behaviors. Additionally, transgender women are stigmatized and victimized in our sample from the Dominican Republic, likely limiting their work opportunities. In combination, these findings suggest the potential of a public health crisis if the social status of transgender women is not elevated. Although anti-discrimination laws exist, these policies are not consistently enforced and do not protect transgender women from being discriminated in work environments, potentially forcing these women to seek alternative work. Further research on if alcohol enables entry into sex work, if alcohol use reduces negative psychosocial effects of being a sex worker, and research that elucidates the personal and social experiences of transgender women in the Dominican Republic is warranted. Specifically, research surrounding the topic of alcohol use and sex work should seek to gauge other parameters of drinking related to type and amount of alcohol use as well as risky behaviors related to binge drinking. Future studies along with this study's findings can inform the development of culturally appropriate, effective harm-reduction strategies for transgender women in the Dominican Republic. 
TABLES

Table 1. Sample Characteristics $(N=291)$

\begin{tabular}{|c|c|c|}
\hline & Mean / N & Std Dev/ \% \\
\hline \multicolumn{3}{|l|}{ Demographic variables } \\
\hline Age & 26.02 & 8.15 \\
\hline Age $18-25$ & 177 & $60.82 \%$ \\
\hline Age 26+ & 114 & $39.18 \%$ \\
\hline \multicolumn{3}{|l|}{ Income } \\
\hline $0-5,000$ Pesos & 125 & $44.80 \%$ \\
\hline Over 5,000 Pesos & 154 & $55.20 \%$ \\
\hline \multicolumn{3}{|l|}{ Employment } \\
\hline Employed & 251 & $88.38 \%$ \\
\hline Unemployed & 33 & $11.62 \%$ \\
\hline \multicolumn{3}{|l|}{ High-Risk Behaviors } \\
\hline \multicolumn{3}{|l|}{ Alcohol Use } \\
\hline Regular alcohol drinker (once a week or more) & 140 & $48.11 \%$ \\
\hline Use of alcohol during sex & 144 & $49.48 \%$ \\
\hline \multicolumn{3}{|l|}{ Engage in sex work } \\
\hline Yes & 108 & $37.11 \%$ \\
\hline No & 183 & $62.89 \%$ \\
\hline \multicolumn{3}{|l|}{ Has not had HIV test in the last 12 months } \\
\hline No HIV test in last 12 months & 228 & $80.85 \%$ \\
\hline HIV test in last 12 months & 54 & $19.15 \%$ \\
\hline \multicolumn{3}{|l|}{ Use of condom when receiving anal sex in past 30 days } \\
\hline Sometimes or never & 27 & $13.78 \%$ \\
\hline Always & 169 & $86.22 \%$ \\
\hline Number of sexual partners in last 6 months & 10.25 & 25.76 \\
\hline \multicolumn{3}{|l|}{ Interpersonal Factors } \\
\hline \multicolumn{3}{|l|}{ Relationship status } \\
\hline Married or living with partner & 21 & $7.22 \%$ \\
\hline In a relationship but not living together & 10 & $3.44 \%$ \\
\hline Polyamorous & 63 & $21.65 \%$ \\
\hline No current partner & 193 & $67.25 \%$ \\
\hline \multicolumn{3}{|l|}{ Experienced verbal insults in the last 3 months } \\
\hline Yes & 139 & $47.93 \%$ \\
\hline No & 151 & $52.07 \%$ \\
\hline \multicolumn{3}{|l|}{ Experienced physical abuse in the last 3 months } \\
\hline Yes & 41 & $14.14 \%$ \\
\hline No & 249 & $85.86 \%$ \\
\hline \multicolumn{3}{|l|}{ Denied a job or fired from one in the last 3 months } \\
\hline Yes & 57 & 80.34 \\
\hline No & 233 & 19.66 \\
\hline Perceived transgender stigma scale (higher=more stigma) & 3.55 & 2.81 \\
\hline
\end{tabular}

Table 2. Bivariate Associations 


\begin{tabular}{|c|c|c|c|c|c|c|}
\hline & \multicolumn{3}{|c|}{$\begin{array}{c}\text { Regular Alcohol Use } \\
\mathrm{N}=291\end{array}$} & \multicolumn{3}{|c|}{$\begin{array}{l}\text { Sex under Influence of Alcohol } \\
\mathrm{N}=291\end{array}$} \\
\hline & Yes & No & $\begin{array}{c}\chi^{2} / \mathrm{t}- \\
\text { test } \\
\end{array}$ & Yes & No & $\chi^{2 / \text { t-test }}$ \\
\hline \multicolumn{7}{|l|}{ Socio-Demographics } \\
\hline Age & $25.56(0.61)$ & $26.44(0.73)$ & $\begin{array}{l}t=-0.91 \\
p=0.36\end{array}$ & $26.19(0.64)$ & $25.85(0.71)$ & $\begin{array}{l}\mathrm{t}=-0.35 \\
\mathrm{p}=0.72\end{array}$ \\
\hline $\begin{array}{l}\text { Monthly income } \\
0-5,000 \text { pesos } \\
\text { Over 5,000 pesos }\end{array}$ & $\begin{array}{l}68(49.64 \%) \\
69(50.36 \%)\end{array}$ & $\begin{array}{l}57(40.14 \%) \\
85(59.86 \%)\end{array}$ & $\begin{array}{c}\chi 2=2.54 \\
p=0.11\end{array}$ & $\begin{array}{l}58(42.03 \%) \\
80(59.97 \%)\end{array}$ & $\begin{array}{l}67(47.52 \%) \\
74(52.48 \%)\end{array}$ & $\begin{array}{c}\chi 2=0.85 \\
p=0.36\end{array}$ \\
\hline $\begin{array}{l}\text { Employment } \\
\text { Employed } \\
\text { Unemployed }\end{array}$ & $\begin{array}{c}122(89.71 \%) \\
14(10.29 \%) \\
\end{array}$ & $\begin{array}{c}129(87.16 \%) \\
19(12.84 \%) \\
\end{array}$ & $\begin{array}{c}\chi 2=0.45 \\
p=0.50\end{array}$ & $\begin{array}{c}129(92.14 \%) \\
11(7.86 \%)\end{array}$ & $\begin{array}{c}122(84.72 \%) \\
22(15.28 \%) \\
\end{array}$ & $\begin{array}{l}\chi^{2}=3.81 \\
p=0.06\end{array}$ \\
\hline \multicolumn{7}{|l|}{ High-Risk Factors } \\
\hline $\begin{array}{l}\text { Engage in sex work } \\
\text { Yes } \\
\text { No }\end{array}$ & $\begin{array}{l}61(43.57 \%) \\
79(56.43 \%)\end{array}$ & $\begin{array}{c}47(31.13 \%) \\
104(68.87 \%)\end{array}$ & $\begin{array}{l}\chi 2=4.82 \\
p<0.05\end{array}$ & $\begin{array}{l}71(49.31 \%) \\
73(50.69 \%)\end{array}$ & $\begin{array}{c}37(25.17 \%) \\
110(47.73 \%)\end{array}$ & $\begin{array}{l}\chi^{2}=18.16 \\
p<0.001\end{array}$ \\
\hline $\begin{array}{l}\text { Has not had HIV test in } \\
\text { last } 12 \text { months } \\
\text { No HIV test } \\
\text { HIV test in last } 12 \text { mo. }\end{array}$ & $\begin{array}{c}7(5.07 \%) \\
131(94.93 \%)\end{array}$ & $\begin{array}{c}17(11.49 \%) \\
131(88.51 \%)\end{array}$ & $\begin{array}{l}\chi 2=3.82 \\
p=0.05\end{array}$ & $\begin{array}{c}4(2.88 \%) \\
135(97.12 \%)\end{array}$ & $\begin{array}{c}20(13.61 \%) \\
127(86.39 \%)\end{array}$ & $\begin{array}{l}\chi 2=3.82 \\
p<0.001\end{array}$ \\
\hline $\begin{array}{l}\text { Use of condom when } \\
\text { receiving anal sex in past } \\
30 \text { days } \\
\text { Sometimes or Never } \\
\text { Always }\end{array}$ & $\begin{array}{l}17(16.67 \%) \\
85(83.33 \%)\end{array}$ & $\begin{array}{l}10(10.64 \%) \\
84(89.36 \%)\end{array}$ & $\begin{array}{c}\chi 2=1.50 \\
p=0.21\end{array}$ & $\begin{array}{l}21(17.80 \%) \\
97(82.20 \%)\end{array}$ & $\begin{array}{c}6(7.69 \%) \\
72(92.31 \%) \\
\end{array}$ & $\begin{array}{l}\chi 2=4.04 \\
p<0.05\end{array}$ \\
\hline $\begin{array}{l}\text { Number of sexual } \\
\text { partners in last } 6 \text { months }\end{array}$ & $13.22(2.66)$ & $7.50(1.52)$ & $\begin{array}{l}t=-1.80 \\
p=0.11\end{array}$ & 13.78 (1.62) & $6.81(1.57)$ & $\begin{array}{l}t=-2.32 \\
p<0.05\end{array}$ \\
\hline \multicolumn{7}{|l|}{ Interpersonal Factors } \\
\hline $\begin{array}{l}\text { Relationship status } \\
\text { Married/living together } \\
\text { Dating, not living together } \\
\text { Polyamorous } \\
\text { No current partner }\end{array}$ & $\begin{array}{c}13(9.35 \%) \\
5(3.60 \%) \\
28(20.14 \%) \\
93(66.91 \%) \\
\end{array}$ & $\begin{array}{c}8(5.41 \%) \\
5(3.38 \%) \\
35(23.65 \%) \\
100(67.57 \%) \\
\end{array}$ & $\begin{array}{c}\chi 2=2.29 \\
p=0.22\end{array}$ & $\begin{array}{c}12(8.45 \%) \\
4(2.82 \%) \\
33(23.24 \%) \\
93(65.49 \%)\end{array}$ & $\begin{array}{c}9(6.21 \%) \\
6(4.14 \%) \\
30(20.69 \%) \\
100(68.97 \%)\end{array}$ & $\begin{array}{c}\chi 2=1.19 \\
p=0.75\end{array}$ \\
\hline $\begin{array}{l}\text { Experienced verbal } \\
\text { insults in the last } 3 \\
\text { months } \\
\text { Yes }\end{array}$ & $\begin{array}{l}24(17.27 \%) \\
11582.73 \%)\end{array}$ & $\begin{array}{l}17(11.26 \%) \\
134(88.74 \%)\end{array}$ & $\begin{array}{c}\chi 2=2.25 \\
p=0.13\end{array}$ & $\begin{array}{l}83(57.64 \%) \\
61(42.36 \%)\end{array}$ & $\begin{array}{l}56(38.36 \%) \\
90(61.64 \%)\end{array}$ & $\begin{array}{l}\chi 2=10.80 \\
p<0.001\end{array}$ \\
\hline $\begin{array}{l}\text { Experienced physical } \\
\text { abuse in the last } 3 \\
\text { months } \\
\text { Yes }\end{array}$ & $\begin{array}{l}73(52.52 \%) \\
66(47.48 \%)\end{array}$ & $\begin{array}{l}66(43.71 \%) \\
85(56.29 \%)\end{array}$ & $\begin{aligned} \chi 2 & =2.05 \\
p & =0.14\end{aligned}$ & $\begin{array}{c}28(19.58 \%) \\
115(80.42 \%)\end{array}$ & $\begin{array}{c}13(8.84 \%) \\
134(91.16 \%)\end{array}$ & $\begin{aligned} \chi 2 & =6.88 \\
p & <0.01\end{aligned}$ \\
\hline $\begin{array}{l}\text { Denied a job or fired } \\
\text { from one in the last } 3 \\
\text { months } \\
\text { Yes }\end{array}$ & $\begin{array}{c}30(21.58 \%) \\
109(78.42 \%)\end{array}$ & $\begin{array}{c}27(17.88 \%) \\
124(82.12 \%)\end{array}$ & $\begin{array}{c}\chi 2=0.63 \\
p=0.42\end{array}$ & $\begin{array}{c}42(29.37 \%) \\
101(70.63 \%)\end{array}$ & $\begin{array}{c}15(10.20 \%) \\
132(89.80 \%)\end{array}$ & $\begin{array}{l}\chi^{2}=16.86 \\
p<0.001\end{array}$ \\
\hline $\begin{array}{l}\text { Perceived transgender } \\
\text { stigma scale } \\
\text { (higher=more stigma) }\end{array}$ & $3.70(0.26)$ & $3.40(0.23)$ & $\begin{array}{l}t=-0.86 \\
p=0.39\end{array}$ & $4.03(0.27)$ & $3.11(0.22)$ & $\begin{array}{l}t=-2.70 \\
p<0.01\end{array}$ \\
\hline
\end{tabular}

Legend: $p<0.1=* p<0.05=* *, p<0.01=* * *$ 


\section{REFERENCES}

Baral, S., Logie, C.H., Grosso, A., Wirtz, A.L., \& Beyrer, C. (2013). Modified social ecological model: a tool to guide the assessment of the risks and risk contexts of HIV epidemics. BMC Public Health, 13, 482.

Baral, S.D., Poteat, T., Strömdahl, S., Wirtz, A.L., Guadamuz, T.E., \& Beyrer, C. (2013). Worldwide burden of HIV in transgender women: a systematic review and meta-analysis. The Lancet Infectious Diseases, 13(3), 214-222.

Bryant, K.J., Nelson, S., Braithwaite, S., \& Roach, D. (2010. Integrating HIV/AIDS and alcohol research. Alcohol Research \& Health, 33(3), 167-178.

Budhwani, H., Hearld, K.R., Hasbun, J., Charow, R., Rosario, S., Tillotson, L...Waters, J. (2017). Transgender female sex workers' HIV knowledge, experienced stigma, and condom use in the Dominican Republic. PLoS One, 12(11), e0186457.

Budhwani, H., Hearld, K.R., Milner, A.N., McGlaughlin, E., Charow, R., RodriguezLauzurique, R.M...Paulino-Ramirez, R. (2017a). Transgender Women’s Drug Use in the Dominican Republic. Transgender Health, 2(1), 188-194.

Budhwani, H., Hearld, K.R., Milner, A.N., Charow, R., McGlaughlin, E., RodriguezLauzurique, R.M...Paulino-Ramirez, R. (2017b). Transgender Women's Experiences with Stigma, Trauma, and Attempted Suicide in the Dominican Republic. Suicide and Life Threatening Behavior. Advance online publication. doi: 10.1111/sltb.12400

Budhwani, H., Turan, B., Hasbun, J., Rosario, S., Tillotson, L., McGlaughlin, E., \& Waters, J. (2017). Association between violence exposure and condom non-use among transgender sex workers in the Dominican Republic: the mediating role of trust. International Journal of STD \& AIDS, 28(6), 608-612.

Clements-Nolle, K., Marx, R., Guzman, R., \& Katz, M. (2001). HIV prevalence, risk behaviors, health care use, and mental health status of transgender persons: implications for public health intervention. American Journal of Public Health, 91(6), 915-921.

Cooper, M.L. (2002). Alcohol use and risky sexual behavior among college students and youth: evaluating the evidence. Journal of Studies on Alcohol, Supplement, (s14), 101-117.

De Graaf, R., Vanwesenbeeck, I., Van Zessen, G., Straver, C.J., \& Visser, J.H. (1995). Alcohol and drug use in heterosexual and homosexual prostitution, and its relation to protection behavior. AIDS Care, 7(1), 35-47.

Dominican Republic. (2015). Constitution of the Dominican Republic. Retrieved from https://www.constituteproject.org/constitution/Dominican_Republic_2015.pdf?lang=en

Hasbún, J.M. (2012). Focus right: Diversity and commonality - a look at female and transgender sex workers in three Caribbean countries. The Caribbean Vulnerable Communities Coalition (CVC), El Centro de Orientacion e Investigacion Integral (COIN), Pan Caribean Partnership Against HIV and AIDS (PANCAP), CARICOM Community Secretariat. Retrieved from CVC website: 
http://www.cvccoalition.org/sites/default/files/SEX_WORKERS_BASELINE_STUDYsmall pdf_com.pdf

Justus, A., Finn, P.R., Steinmetz, J. (2000). The Influence of Traits of Disinhibition on the Association Between Alcohol Use and Risky Sexual Behavior. Alcoholism: Clinical and Experimental Research, 24(7), 1028-1035.

Kelly, J., Davis, C., \& Schlesinger, C. (2015). Substance use by same sex attracted young people: prevalence, perceptions and homophobia. Drug and Alcohol Review, 34(4), 358-365.

Krogstad, D.J., Diop, S., Diallo, A., Mzayek, F., Keating, J., Koita, O.A., \& Toure, Y.T. (2010). Informed Consent in International Research: The Rationale for Different Approaches. The American journal of Tropical Medicine and Hygiene, 83(4), 743-747.

Leonard, W., Pitts, M., Mitchell, A., Lyons, A., Smith, A., Patel, S...Barrett, A. (2012). Private lives 2 - The second national survey on the health and wellbeing of gay, lesbian, bisexual, transgender (GLBT) Australians. Melbourne: The Australian Research Centre in Sex Health and Society, La Trobe University. Retrieved from the GLHV website: https://www.glhv.org.au/sites/default/files/PrivateLives2Report.pdf

Li, Q., Li, X., \& Stanton, B. (2010). Alcohol use among female sex workers and male clients: an integrative review of global literature. Alcohol and Alcoholism, 45(2), 188-199.

Marshall, P.A. (2007). Ethical challenges in study design and informed consent for health research in resource-poor settings. Special Topics in Social, Economic and Behavioural (SEB) Research report series, No. 5. Retrieved from the World Health Organization website: http://apps.who.int/iris/bitstream/handle/10665/43622/9789241563383_eng.pdf?sequence=1 \&isAllowed $=y$

Nadal, K.L., Davidoff, K.C., \& Fujii-Doe, W. (2014). Transgender women and the sex work industry: roots in systemic, institutional, and interpersonal discrimination. Journal of Trauma \& Dissociation, 15(2), 169-183.

Onvomaha Tindana, P., Kass, N., \& Akweongo, P. (2006). The Informed Consent Process in a Rural African Setting: A Case Study of the Kassena-Nankana District of Northern Ghana. IRB, 28(3), 1-6.

Operario, D., \& Nemoto, T. (2010). HIV in transgender communities: syndemic dynamics and a need for multicomponent interventions. Journal of Acquired Immune Deficiency Syndrome, 55(Suppl 2), S91-93.

Poteat, T., Wirtz, A.L., Radix, A., Borquez, A., Silva-Santisteban, A., Deutsch, M.B...Operaario, D. (2015). HIV risk and preventive interventions in transgender women sex workers. The Lancet, 385(9964), 274-286.

Poundstone, K.E., Strathdee, S.A., \& Celentano, D.D. (2004). The social epidemiology of human immunodeficiency virus/acquired immunodeficiency syndrome. Epidemiologic Review, 26, 22-35. 
Rao, A., Stahlman, S., Hargreaves, J., Weir, S., Edwards, J., Rice, B...Baral, S. (2017). Sampling key populations for HIV surveillance: results from eight cross-sectional studies using respondent-driven sampling and venue-based snowball sampling. JMIR Public Health and Surveillance, 3(4), e72.

Reback, C.J., \& Fletcher, J.B. (2014). HIV prevalence, substance use, and sexual risk behaviors among transgender women recruited through outreach. AIDS Behavior, 18(7), 1359-1367.

Reback, C.J., Rünger, D., \& Fletcher, J.B. (2017). Physical and/or Sexual Abuse are Associated with Negative Health Outcomes among Transgender Women of Color Living with HIV. Violence and Gender, 4(4), 130-136.

Roche, K., \& Keith, C. (2014). How stigma affects healthcare access for transgender sex workers. British Journal of Nursing, 23(21), 1147-1152.

Sausa, L.A., Keatley, J., \& Operario, D. (2007). Perceived Risks and Benefits of Sex Work among Transgender Women of Color in San Francisco. Archives of Sexual Behavior, 36(6), 768-777.

Shaghaghi, A., Bhopal, R.S., \& Sheikh, A. (2011). Approaches to recruiting 'hard-to-reach' populations into research: a review of the literature. Health Promotion Perspectives, 1(2), 8694.

Smith, A.M., Lindsay, J., \& Rosenthal, D.A. (1999). Same-sex attraction, drug injection and binge drinking among Australian adolescents. Australian and New Zealand Journal of Public Health, 23(6), 643-646.

Stotzer R. (2009). Violence against transgender people: A review of United States data. Aggression and Violent Behavior, 1493), 170-179.

Sugano, E., Nemoto, T., \& Operario, D. (2006). The Impact of Exposure to Transphobia on HIV Risk Behavior in a Sample of Transgendered Women of Color in San Francisco. AIDS and Behavior, 10(2), 217-225.

Tekola, F., Bull, S.J., Farsides, B., Newport, M.J., Adeyemo, A., Rotimi, C.N., \& Davey, G. (2009). Tailoring consent to context: designing an appropriate consent process for a biomedical study in a low income setting. PLoS Neglected Tropical Diseases, 3(7), e482.

Turan, B., Budhwani, H., Fazeli, P.L., Browning, W.R., Raper, J.L., Mugavero, M.J., \& Turan, J.M. (2017). How does stigma affect people living with HIV? The mediating roles of internalized and anticipated HIV stigma in the effects of perceived community stigma on health an psychosocial outcomes. AIDS and Behavior, 21(1), 283-291.

Winter, S., Diamond, M., Green, J., Karasic, D., Reed, T., Whittle, S., \& Wylie, K. (2016). Transgender people: health at the margins of society. The Lancet, 388(10042), 390-400.

Weir, S.S., Tate, J., Hileman, S.B., Khan, M., Jackson, E., Johnston, A., \& Herman, C. (2005). Priorities for Local AIDS Control Efforts: A Manual for Implementing the PLACE 
Method. Retrieved from the Measure Evaluation Project website:

https://www.measureevaluation.org/resources/publications/ms-05-13

Winter, S., Settle, E., Reisner, S., Cabral, M., Knudson, G., \& Baral, S. (2016). Synergies in health and human rights: a call to action to improve transgender health. The Lancet, 388(10042), 318-321.

Woolf-King, S.E., \& Maisto, S.A. (2011). Alcohol Use and High-Risk Sexual Behavior in Sub-Saharan Africa: A Narrative Review. Archives of Sexual Behavior, 40(1), 17-42.

World Health Organization. (2014). Global status report on alcohol and health. Retrieved from WHO website:

http://apps.who.int/iris/bitstream/handle/10665/112736/9789240692763_eng.pdf;jsessionid= 1CCE4613F48ED84BC710C01896B4B388? sequence=1 